\title{
HermosiArte Talleres de música para jóvenes de colonias populares
}

\author{
Fabio Murillo Sánchez*
}

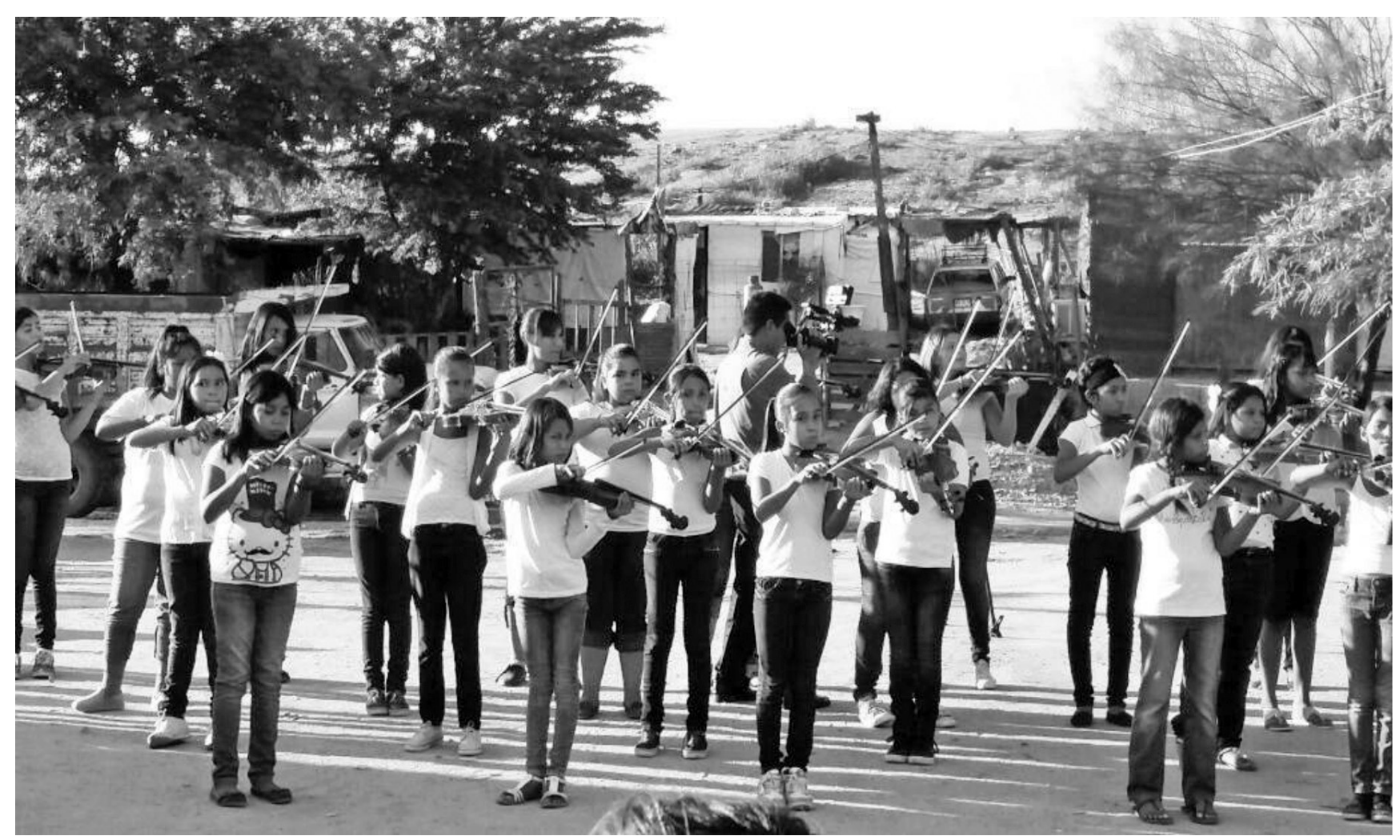

La organización fue creada como una entidad encaminada a impulsar sin ánimo de lucro, la educación cultural en la niñez y la adolescencia, cuyo principio es la no discriminación, pensando especialmente en niños y adolescentes en situación de vulnerabilidad y de bajos recursos, comunidades indígenas y personas con discapacidad, que de otra forma tal vez les sería imposible tener algún tipo de acercamiento con la formación musical.
Nuestra labor de formación y reintegración social de la niñez y la juventud inmersa en actividades delictivas o en riesgo, constituyen el valor de una entidad como HermosiArte.

* Director fundador de HermosiArte Sonora A.C. Desde 2012 atiende a niños de comunidades vulnerables en la ciudad de Hermosillo a través de la enseñanza de las artes con énfasis en música. Originario de Colombia dedica su tiempo a pacificar a través de la cultura.

\section{Savía}




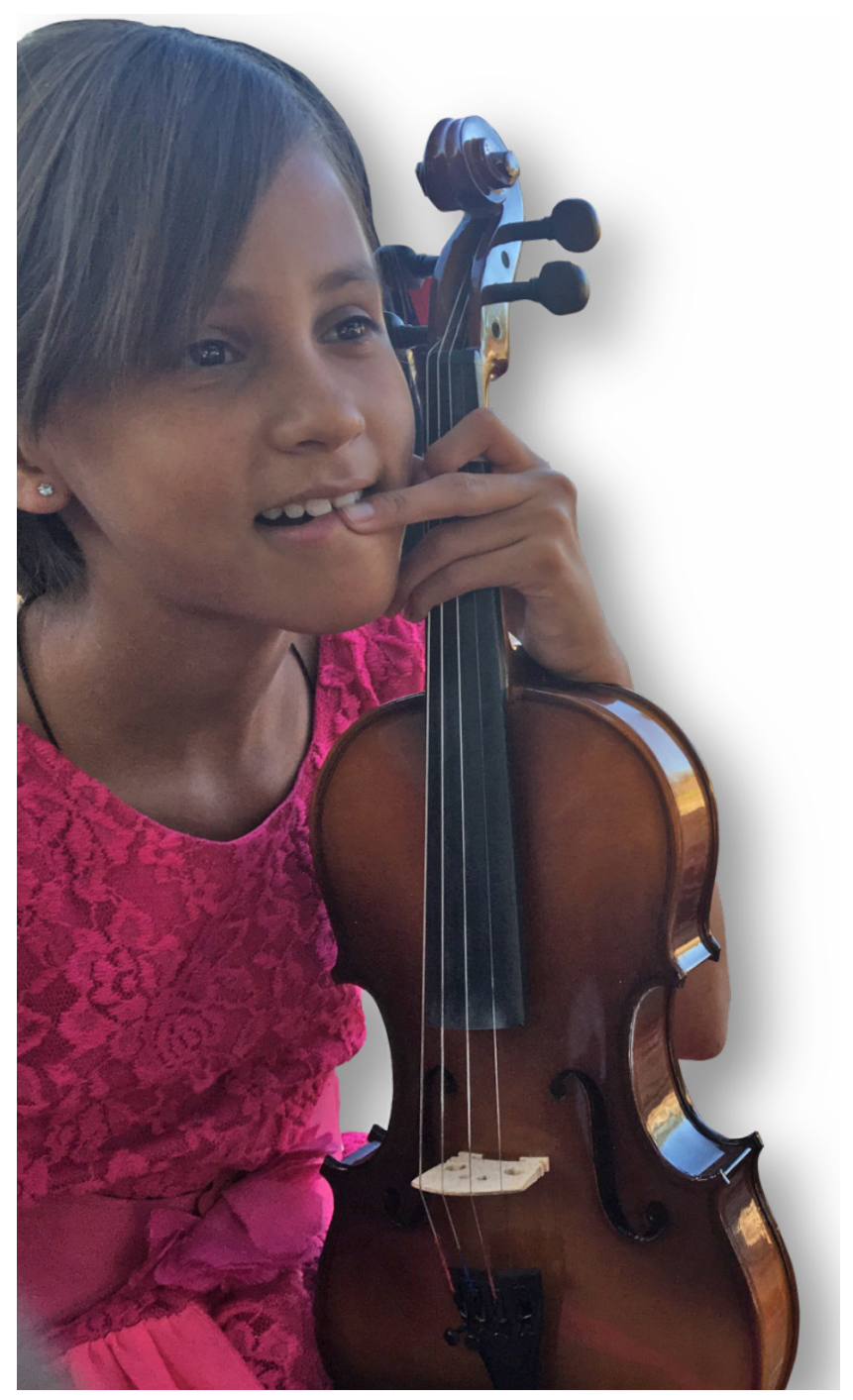

Fundada en 2011 y formalizada en 2012 como HermosiArte Hermosillo A.C. y HermosiArte I.A.P. en 2016.

HermosiArte surge del sueño por mejorar el medio de niños y adolescentes que nacen con la vida aparentemente truncada de opciones de progreso y bienestar. Nuestro fundador, Lic. Fabio Murillo Sánchez, es el ejemplo vivo de la pertinencia de este programa: un niño nacido en Colombia, víctima de la violencia y la guerrilla que le arrebató a su padre a los seis años, quien teniendo como opción la venganza, la violencia y una vida con pase directo a las armas y a la delincuencia, fue rescatado por medio de la educación y la música. Tuvo la opción de una vida diferente que hasta hoy en día lo ha llevado a compartir y transmitir su experiencia, a través de esta organización humanitaria desarrollada en Hermosillo, Sonora, México.

\section{Misión}

Reintegrar a la sociedad por medio de la enseñanza del arte y una atención integral, a niños y adolescentes en estado de vulnerabilidad, a través de programas asistenciales y de desarrollo humano que les permita encontrar opciones dignas para la transformación de sus vidas.

\section{Visión}

Ser el centro de desarrollo humano y asistencial líder en el estado para atención de niños y adolescentes de escasos recursos en riesgo de calle, ofreciendo educación, atención integral y albergue temporal, en instalaciones amplias, armoniosas, con personal capacitado y voluntariado con vocación de servicio, que inspire a nuestros jóvenes en la realización de sus propósitos de vida.

\section{Hechos}

- 112336538 población mexicana

- 2850330 población sonorense

- 884273 población de Hermosillo (INEGI, 2015)

- $\quad 32.7 \%$ población en pobreza de Sonora (CONEVAL, 2014)

- 87039 adolescentes entre 11 y 16 años

- 75001 niños entre 6 y 10 años en Hermosillo

- 266 víctimas procesadas por violencia doméstica

- 141 pandillas Hermosillo

- 4100 miembros registrados

- 1125 procesos criminales contra adolescentes

- 828 adolescentes procesados y detenidos en centros de rehabilitación social en 2015

- 2.5 millones de niños desarrollando actividades económicas en Sonora

- Adolescentes (40\%) representatividad de embarazos en Sonora 2016

- 23809 población en Hermosillo (SEDESOL, 2015)

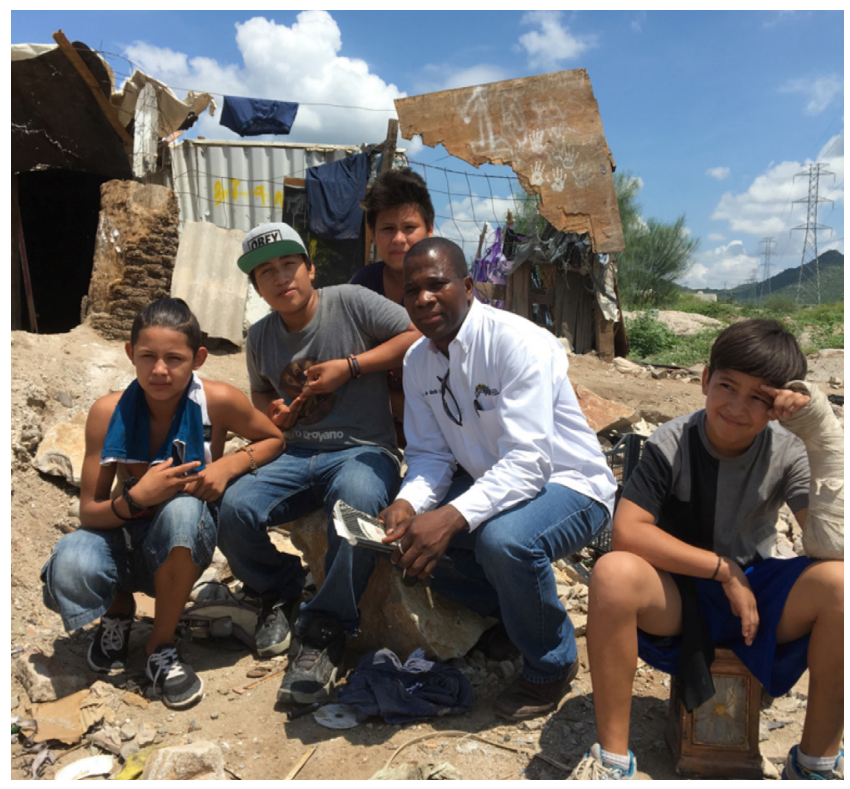




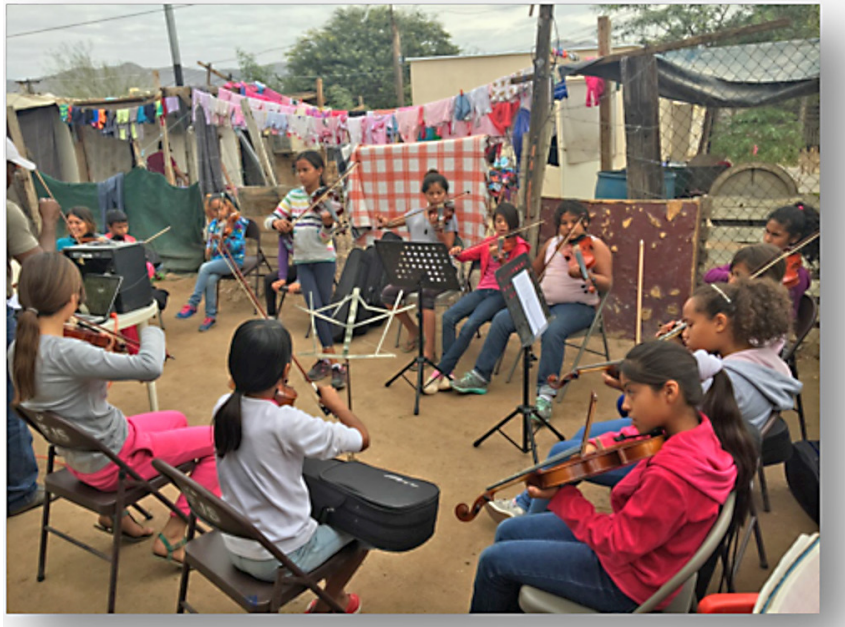

Retos HermosiArte:

- Deserción escolar

- Salud Mental

- Narcotráfico

- Crimen

- Explotación sexual

- Embarazos adolescentes

- Prostitución

- Adicciones

\section{¿Cómo lo hacemos?}

- Gestión de talento: Identificamos en comunidad aptitudes y habilidades musicales.

- Asistencialismo: Apoyo constante e integral al entorno familiar para apoyo y mejora de condiciones de vida.

- Desarrollo humano: Profesionalización y capacitación constante de nuestros miembros.

- Educación escolar: Buscamos la reintegración y permanencia de nuestros niños en la educación.

- Fomento de hábitos saludables: Atención a la salud e implementación de programas de hábitos saludables y estímulo deportivo.

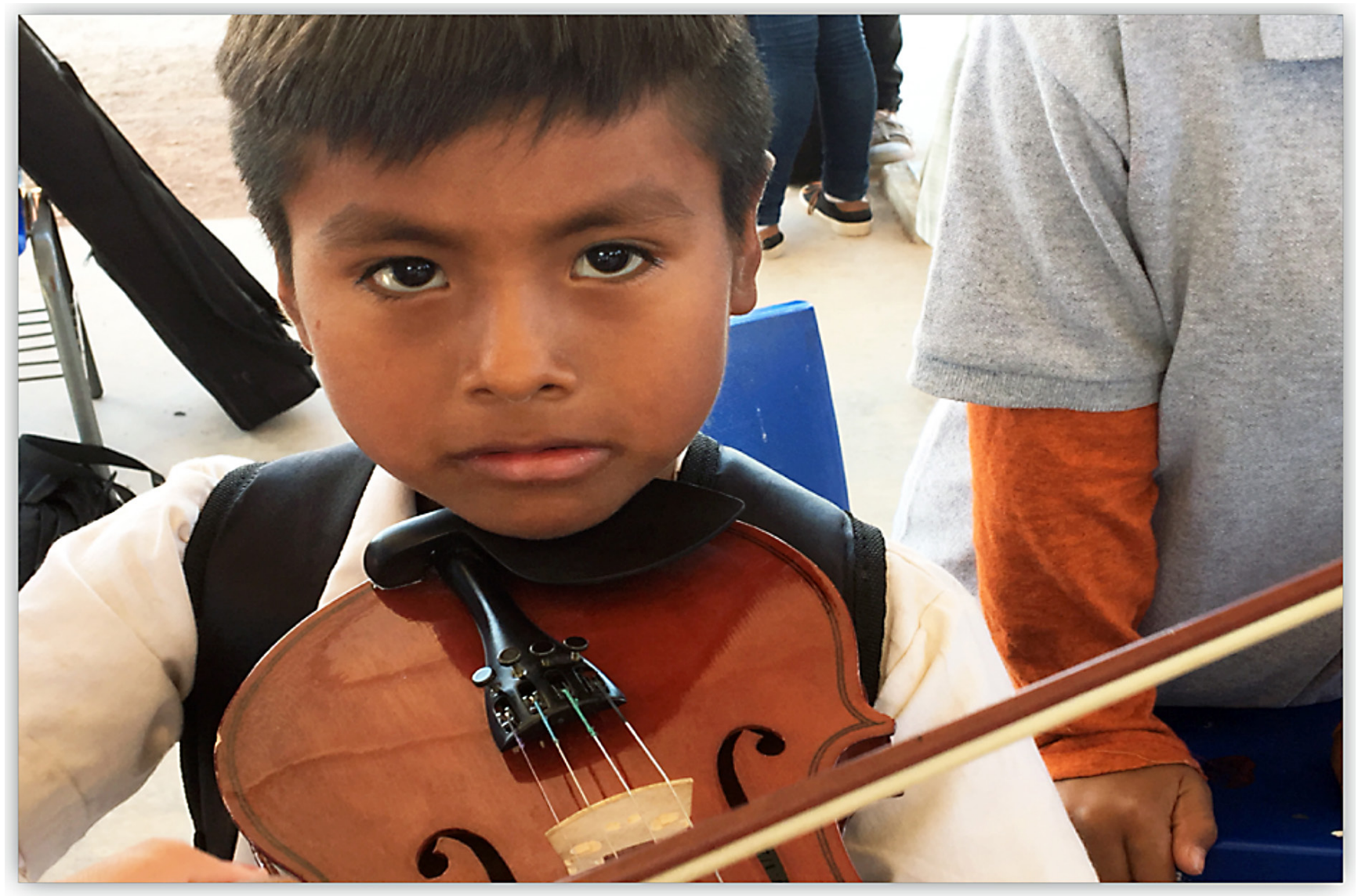




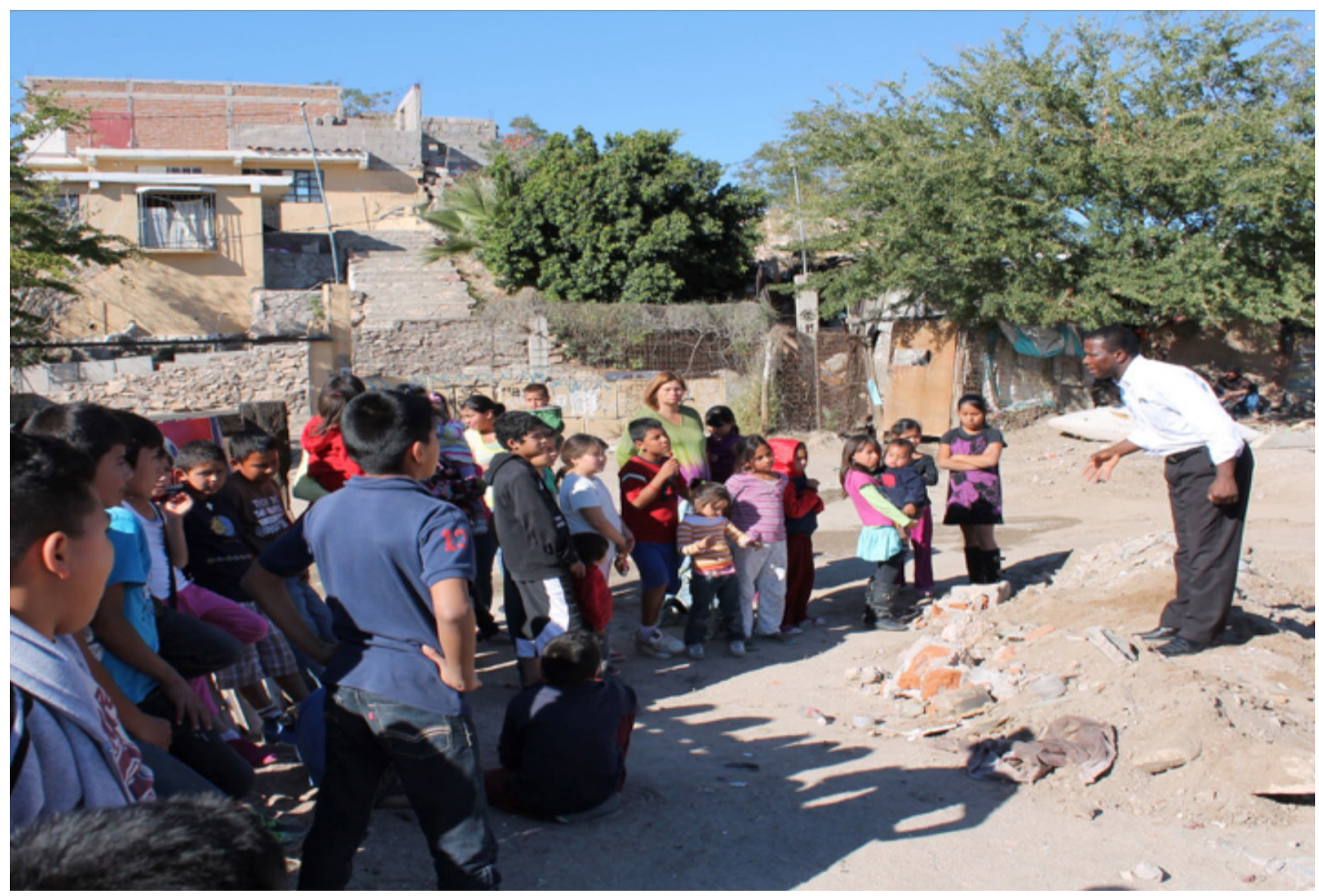

Progresar frente a sus desafíos más complejos
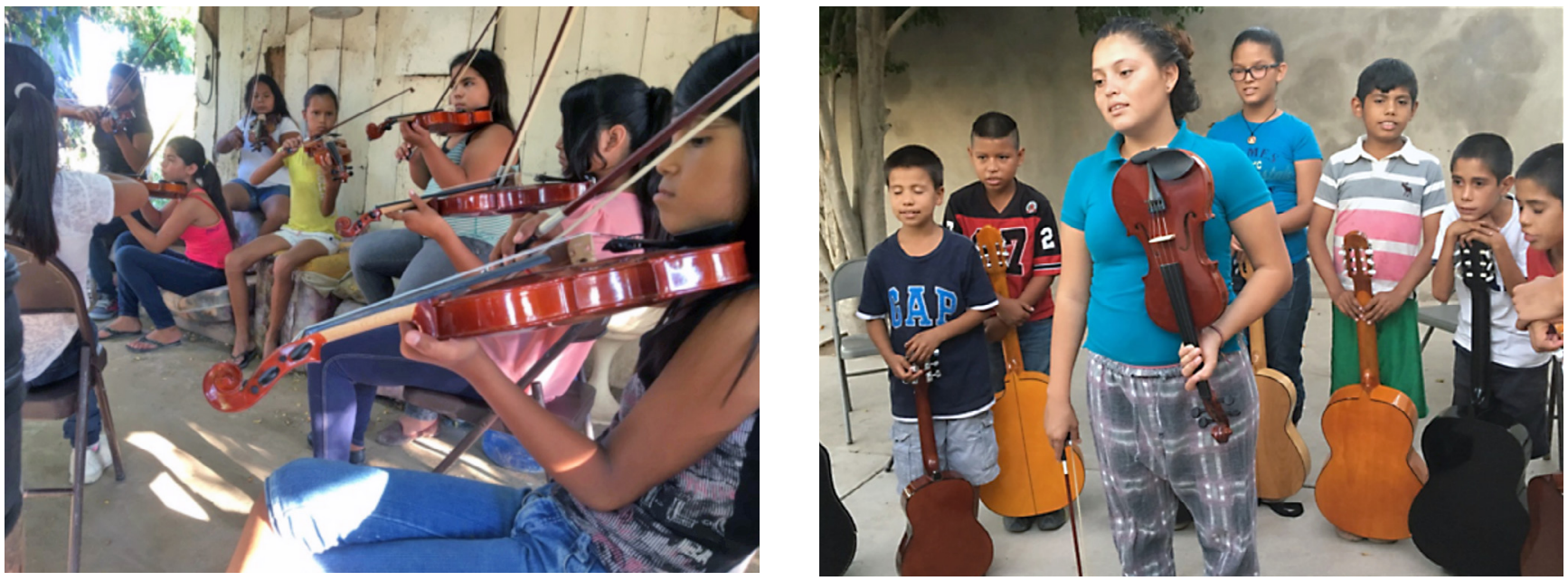


\section{Nuestras comunidades}

- Programa de nutrición

- Intervención psicosocial

- Talleres comunitarios

- Presentaciones musicales

- Becas académicas y musicales

- Esparcimiento

- Servicios de atención a la salud comunitaria

- 650 niños en registro fijo, más población variable.
Fraccionamientos irregulares alrededor de Hermosillo

Norberto Ortega

Guayacanes

Poblado Miguel Alemán

Invasión Altares

El Saucito

El Mariachi

Lomas del Norte

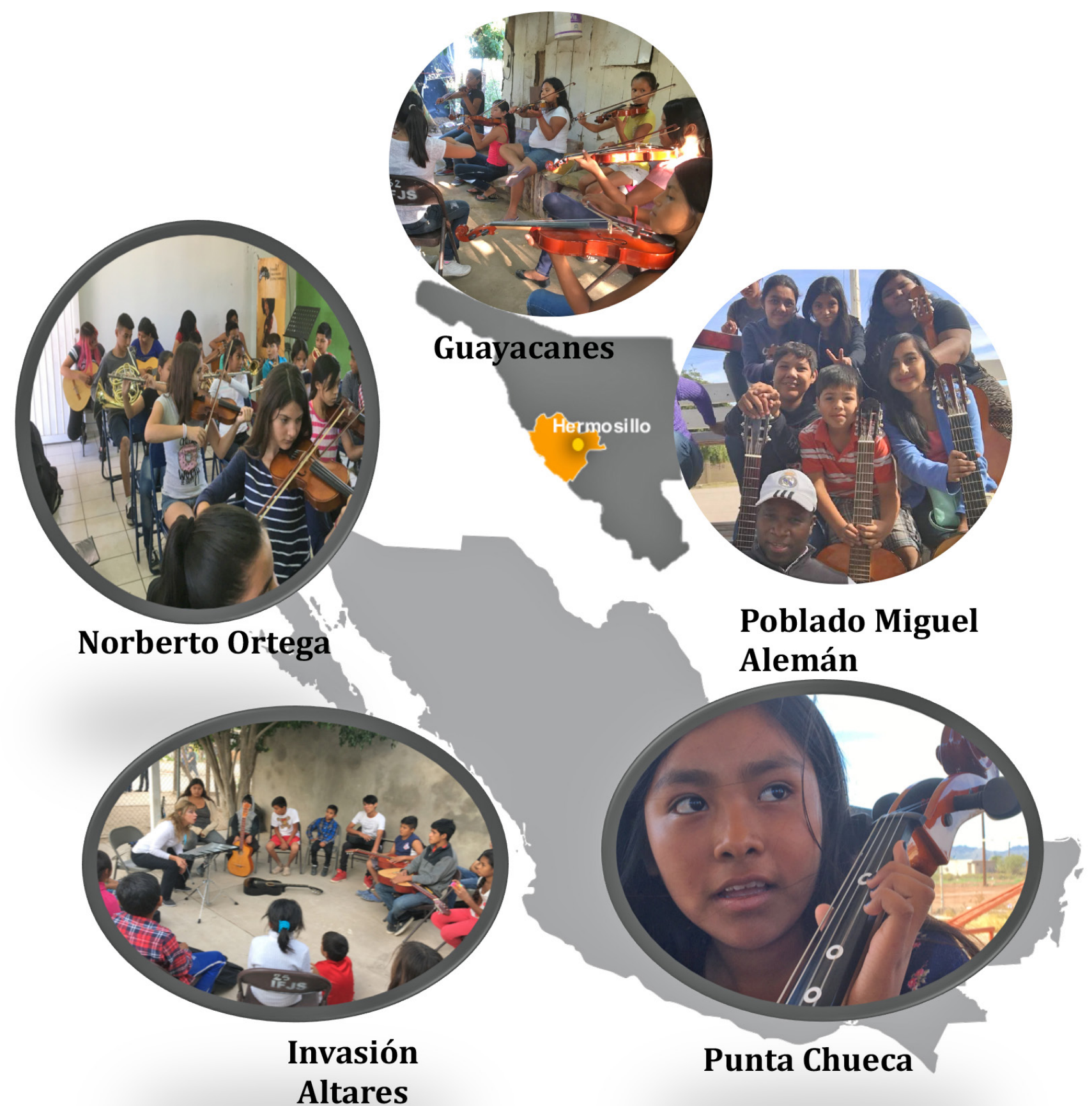




\section{En comunidades indígenas}
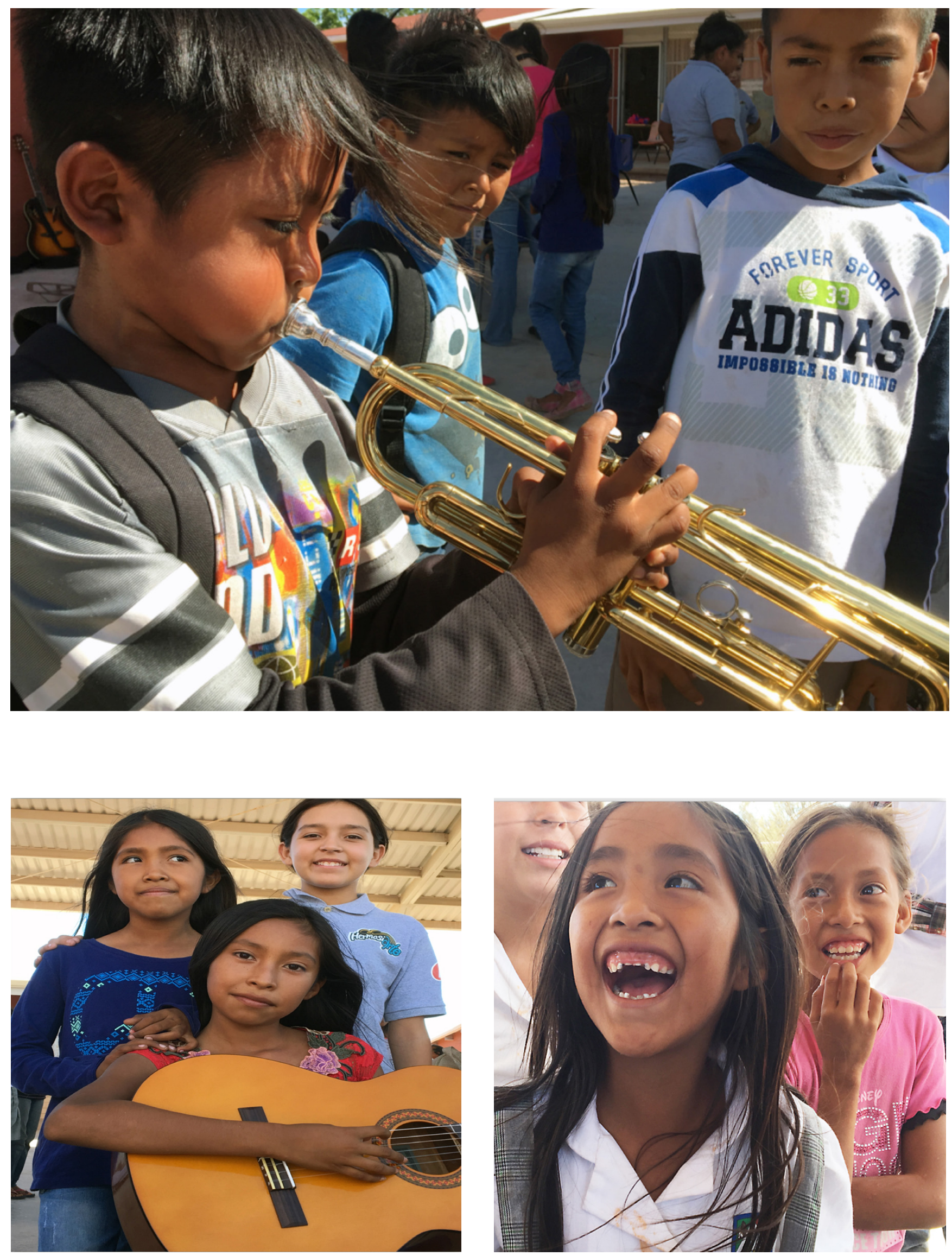
Ojos que no ven música que se siente
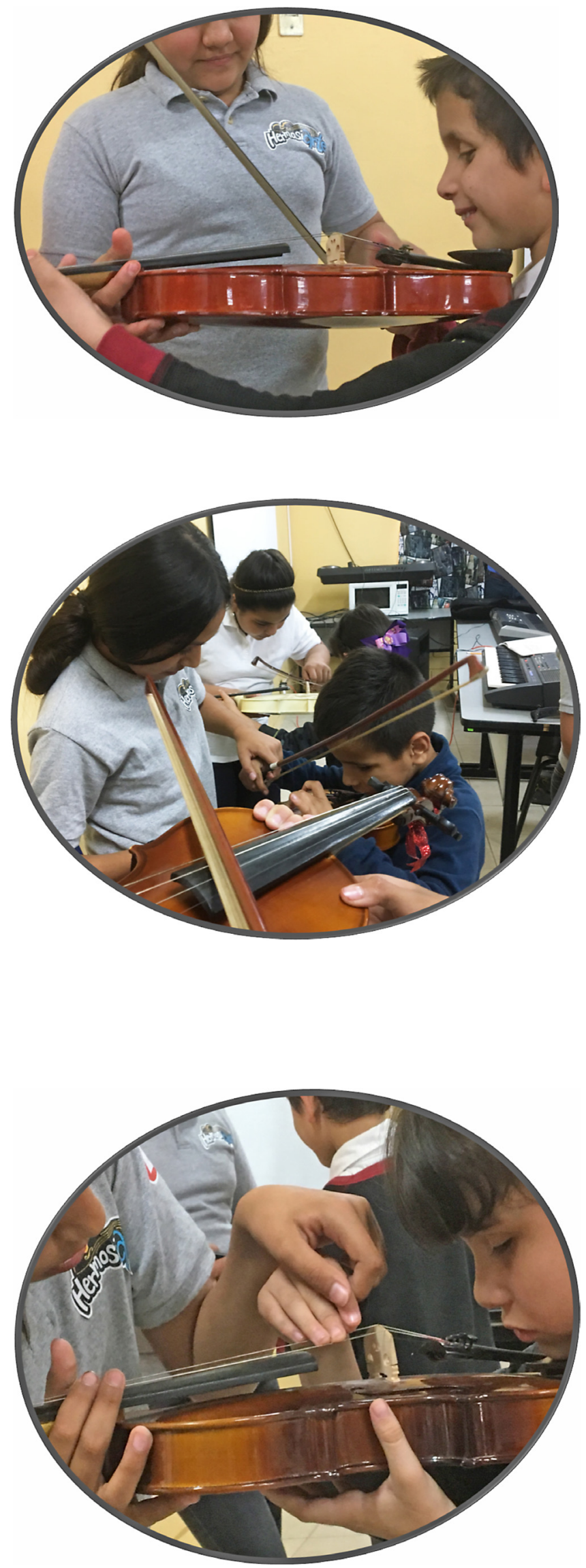

El empoderamiento y reducción de la pobreza mediante la cultura
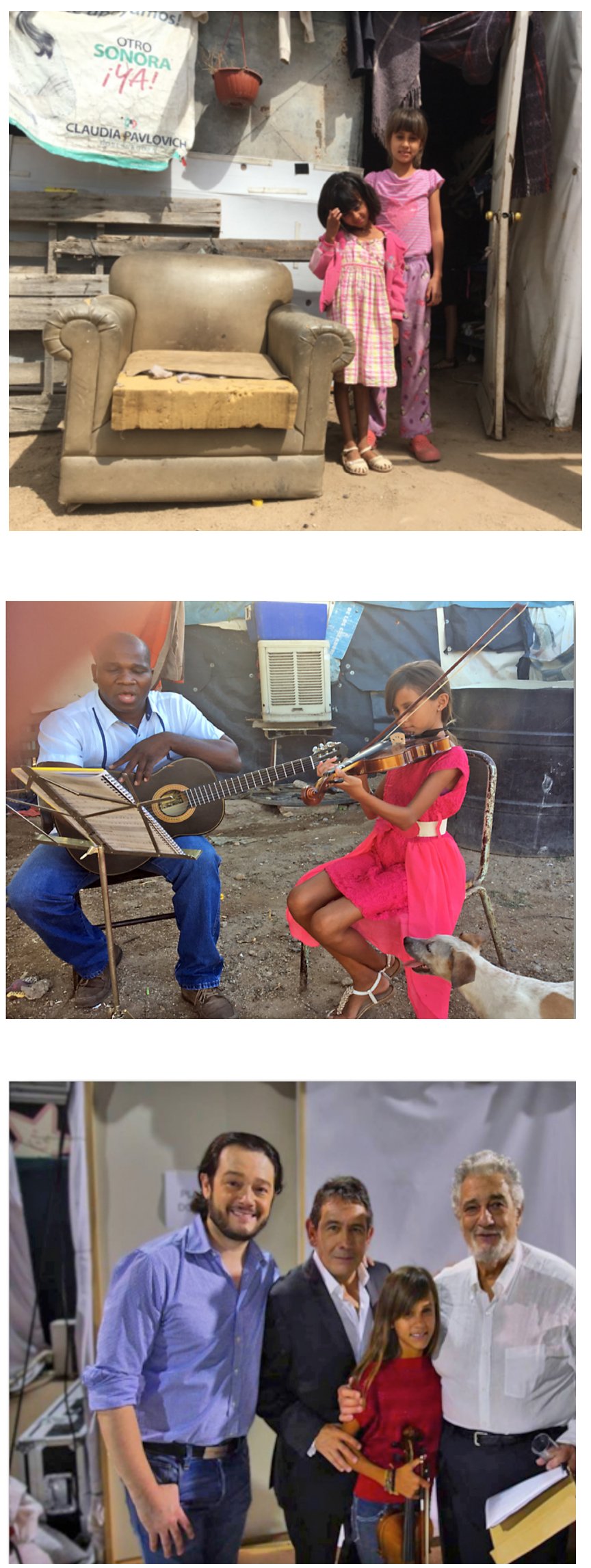

\section{Savîa}

